\title{
CORRIGENDUM
}

\section{Overweight in singletons compared to children with siblings: the IDEFICS study}

M Hunsberger, A Formisano, LA Reisch, K Bammann, L Moreno, S De Henauw, D Molnar, M Tornaritis, T Veidebaum, A Siani and L Lissner

Nutrition and Diabetes (2012) 2, e56; doi:10.1038/nutd.2012.28; published online 10 December 2012

Correction to: Nutrition and Diabetes (2012) 2: e35; doi:10.1038/ nutd.2012.8; published online 2 July 2012

Since the publication of this article the authors have noticed an error in the numbering of the references 8-11.

The correct order of references is as follows:

8 Christakis NA and Fowler JH. The spread of obesity in a large social network over 32 years. N Engl J Med 2007; 357: 370-379.
9 Auld MC. Effect of large-scale social interactions on body weight. J Health Econ 2011; 30: 303-316.

10 Júlíusson PB, Eide GE, Roelants M, Waaler PE, Hauspie R, Bjerknes R. Overweight and obesity in Norwegian children: prevalence and sociodemographic factors. Acta Paediatrica 2010; 99: 900-905.

11 Price J. Parent-child quality time: does birth order matter? J Human Resources 2008; 43: 240-265.

The authors would like to apologise for this error. 